\title{
MORPHOLOGY AND KINETICS OF GRAIN BOUNDARY PRECIPITATION IN ALLOY ATI 718PLUS ${ }^{\circledR}$
}

\author{
A. Casanova ${ }^{1}$, M. Hardy ${ }^{2}$, C.M.F. Rae ${ }^{1}$ \\ Department of Materials Science and Metallurgy, University of Cambridge, Pembroke Street, \\ Cambridge CB2 3QZ, UK \\ ${ }^{2}$ Rolls-Royce plc, PO Box 31, Derby DE24 8BJ, UK
}

Keywords: 718Plus, TTT diagram, $\eta$ phase, $\delta$ phase, EBSD, TEM

\begin{abstract}
Alloy ATI 718Plus ${ }^{\circledR}$ relies upon the co-precipitation of secondary phases $\eta$ and $\delta$ at the grain boundaries to control grain structure during processing. Abundant precipitation can occur in the billet material during heating time before sub-solvus forging, which persists to a certain extent in the microstructure of the final component and modifies the compression flow stress. As these phases are sensitive to the thermo-mechanical history of the material, any such inhomogeneity in the billet stock will be reflected in the precipitate population.

A TTT diagram of second-phase precipitation in 718Plus billet material is presented. The effects of initial grain size and residual strain on the morphology and precipitation kinetics of the precipitates have been investigated by scanning and transmission electron microscopy and EBSD. Plastic deformation was found to determine precipitate morphology, largely through its effect on the degree of coherency at the precipitate/matrix interface. Approaches to modify the precipitate growth mechanism through a deformation process are suggested.
\end{abstract}

\section{Introduction}

ATI 718 Plus ${ }^{\circledR}$ is a polycrystalline Ni-base superalloy with applications in static and rotating aero-engine components. It has an improved temperature capability over Inconel 718, combined with equally good mechanical properties and processability [1]. For these reasons, 718Plus is a promising candidate to replace other more expensive $\gamma^{\prime}$-strengthened alloys such as Waspaloy or Udimet $720 \mathrm{Li}$ in applications where the service temperature does not exceed $675{ }^{\circ} \mathrm{C}$ [2].

Unlike alloy 718 , strengthened by the precipitation of the metastable $\gamma^{\prime \prime}$-phase $\left(\mathrm{Ni}_{3} \mathrm{Nb}, \mathrm{D} 0_{22}\right.$, tetragonal), the main hardening phase in 718Plus is $\gamma^{\prime}\left(\mathrm{Ni}_{3}[\mathrm{Al}, \mathrm{Nb}, \mathrm{Ti}], \mathrm{L}_{2}\right.$, cubic), which provides a higher thermal stability [3-5]. In order to strengthen the grain boundaries and control grain size, secondary phase particles with a plate-like morphology can be precipitated through adequate heat treatment. The nature of the grain boundary precipitates has been a subject of recent debate. They were initially identified as $\delta$ phase $\left(\mathrm{Ni}_{3} \mathrm{Nb}, \mathrm{D} 0_{\mathrm{a}}\right.$, orthorhombic) as in alloy $718[5,6]$. While some early reports by Xie et al. indicated the presence of a hexagonal phase in 718 Plus [7,8], this possibility remained largely unexplored. Recently Pickering et al. clarified the issue and demonstrated that grain boundary particles in 718Plus are principally composed of $\eta$ phase $\left(\mathrm{Ni}_{6}[\mathrm{Al}, \mathrm{Ti}] \mathrm{Nb}, \mathrm{D}_{24}\right.$, hexagonal) interleaved with layers of $\delta$ [9]. It has been suggested that this configuration serves to accommodate local compositional variations, and that the ratio between the two phases could depend on the thermo-mechanical history of the material [10]. However, $\eta$ appears to be the main constituent in the majority of precipitates, while the $\delta$ layers, sometimes only a few atomic layers thick, can only be detected using high-resolution techniques. 
The effect of grain boundary precipitation on the mechanical properties of alloy 718Plus has received a good deal of attention, and appears to depend strongly on the volume fraction, morphology and location of the precipitates $[5,11,12]$. Nevertheless, it is generally accepted that a small amount of rod-shaped particles, homogeneously distributed over most grain boundaries, is necessary to prevent notch sensitivity at high temperature and improve resistance to intergranular crack propagation [13]. In addition, the pinning effect of the grain boundary precipitates leads to a better control of the grain structure during hot working operations taking place below the relevant solvus temperature.

In this study, the microstructure of 718 Plus wrought billet has been characterized as the starting stock for the production of aero-engine disc forgings. The manufacture of disc components typically involves hot working the wrought billet in several steps, so as to develop the required geometry and refine the microstructure, followed by heat treatment to optimize the different precipitate populations. Since heating times for industrial-scale forging operations range from 30 minutes to 3 hours, the effect of hold time at temperatures within the range for $\eta$ and $\delta$ precipitation has been studied through several short-term annealing heat treatments. A TTT diagram of secondary phase precipitation in the billet has been produced, with a focus on the influence of starting grain size and residual strain on phase fraction and morphology. The effect of precipitation in the billet on the flow stress during forging has been investigated by hot compression mechanical testing.

\section{Background}

Time-temperature-transformation (TTT) diagrams describe the kinetics of phase precipitation in Ni-superalloys and are essential for high temperature application. These relationships have been thoroughly investigated for alloy 718: the first TTT diagram was presented by Eiselstein in 1965 [14] and many investigators since have incorporated the subsequent developments on the metallurgy of the alloy [15-17]. The precipitation of $\delta$ phase in alloy 718, which essentially fulfills the same functions as the $\eta / \delta$ phases in 718 Plus, has received particular attention [18-20]. It is clear from the published literature that the kinetics and type of precipitation of $\delta$ phase in alloy 718 are dependent on the nature of the starting material, most especially on the degree of residual strain [21,22], which rapidly accelerates nucleation.

The interest in alloy 718Plus has prompted the appearance of several studies tackling the same issue, although the information already available is naturally more limited. The precipitation kinetics of the strengthening phase $\gamma^{\prime}$ has first been studied in terms of hardness [7,23] and later completed with TEM observations [23] and modeling simulations [5,24]. TTT diagrams of $\eta / \delta$ phase precipitation have been published both in solution-treated (strain free) [5,7] and forged $[5,13,25]$ material. These results suggested a dependency of the $\eta / \delta$ precipitation with respect to residual strain similar to alloy 718 . It also appears that $\eta / \delta$ nucleation is structure-sensitive, occurring first on grain boundaries, then on twins and eventually in grain interiors [5].

The effect of strain on $\eta / \delta$ precipitation in 718 Plus has proved to be critical by subsequent studies. Andersson et al. [26] first reported the difficulty of re-precipitating $\eta / \delta$ in solutioned strain-free material and McDevitt [27] later confirmed the crucial role of residual strain from hot working and grain boundary defects in $\eta / \delta$ precipitation. Once the dependency of second phase precipitation on the starting material conditions has been established, it becomes necessary to perform a specific study on wrought billet material in order to examine the characteristics of $\eta / \delta$ precipitation during hold time before forging. 


\section{Experimental Methods}

\section{$\underline{\text { Materials }}$}

The 718Plus billet material used in this study was produced by ATI Speciality Materials (Allegheny Technologies Incorporated, Monroe, NC, USA) and supplied by Rolls-Royce Deutschland Ltd. \& Co KG (RRD). The alloy, whose composition is presented in Table I, was first triple melted (VIM / ESR / VAR) to produce a high quality ingot, homogenized and converted into a wrought product in billet form. The billet was received in the as-forged condition, after the surface was peeled and polished to a final diameter of $229 \mathrm{~mm}$.

Table I. Chemical composition of 718Plus material used in this study in wt.\%

\begin{tabular}{cccccccccccc}
\hline $\mathrm{Cr}$ & $\mathrm{Co}$ & $\mathrm{Fe}$ & $\mathrm{Mo}$ & $\mathrm{W}$ & $\mathrm{Nb}$ & $\mathrm{Al}$ & $\mathrm{Ti}$ & $\mathrm{P}$ & $\mathrm{B}$ & $\mathrm{C}$ & $\mathrm{Ni}$ \\
\hline 17,97 & 9,09 & 9,64 & 2,69 & 1,02 & 5,49 & 1,6 & 0,75 & 0,009 & 0,005 & 0,022 & $\mathrm{Bal}$ \\
\hline
\end{tabular}

A slice $15 \mathrm{~mm}$ thick was cut from the top of the billet and $10 \times 10 \times 7.5 \mathrm{~mm}^{3}$ samples extracted from two locations: core ( $0-35 \%$ of the radius) and $\mathrm{rim}$ ( $60-95 \%$ of the radius), as indicated in Figure 1. Four samples along the radius were investigated in the as-received state (AR); the rest were put in pairs of core and rim specimens, and given single isothermal heat treatments. 16 pairs were annealed at temperatures $925^{\circ} \mathrm{C}, 950{ }^{\circ} \mathrm{C}, 975{ }^{\circ} \mathrm{C}$ and $1000^{\circ} \mathrm{C}$ for times $20 \mathrm{~min}, 1$ hour, 3 hours and 10 hours to produce a TTT diagram of $\eta / \delta$ phase precipitation. Two other pairs were heat-treated at $900{ }^{\circ} \mathrm{C}$ and $960{ }^{\circ} \mathrm{C}$ for $81 \mathrm{~h}$ to estimate the equilibrium phase fractions. All samples were water quenched after annealing and a slice cut out for metallographic examination in the axial-radial plane of the billet frame of reference.

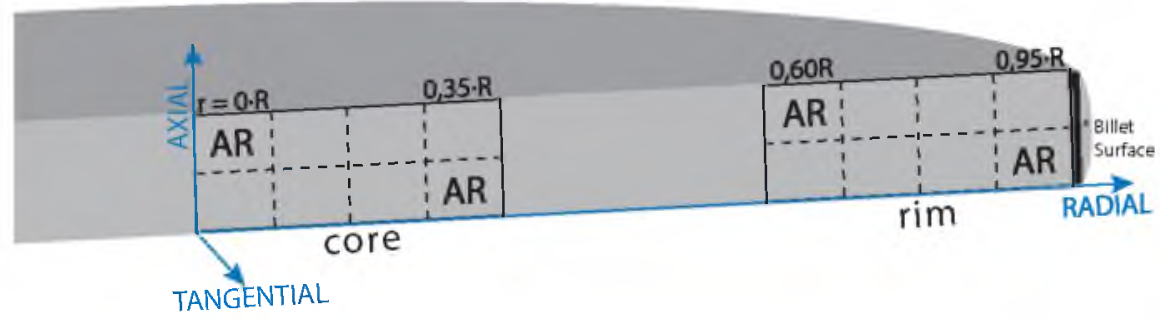

Figure 1. Diagram of the core and rim locations within a slice of billet material

\section{Quantitative metallography}

For imaging and quantification of the precipitated $\eta$ and $\delta$ phases, the specimens were electroetched to reveal the $\eta / \delta$ and $\gamma^{\prime}$ particles in a solution of $10 \mathrm{vol} \%$ phosphoric acid in distilled water at $2.5 \mathrm{~V}$. At the level of resolution in this study it is impossible to differentiate the $\eta$ and $\delta$ phases, as they are combined within single particles, and the results presented account for the combined $\eta+\delta$ content. Secondary electrons (SE) were used to image the specimens in a scanning electron microscope (SEM) Jeol 5800LV. The micrographs were subsequently processed for image analysis using the software ImageJ. Grayscale images were converted to binary maps by manually adjusting the threshold and, when necessary, spherical $\gamma^{\prime}$ particles were removed using circularity and particle size criteria. This procedure can overestimate slightly the $\eta / \delta$ content due to the relief effect induced by the etching. The average values were calculated over a minimum of five micrographs at a magnification of 1000 in order to accurately represent the different types of microstructures encountered. 


\section{Differential Scanning Calorimetry}

The solvus temperatures of the $\gamma^{\prime}$ and $\eta$ and $\delta$ phases obtained from microstructural observations were confirmed using a Netzsch STA 404 differential scanning calorimetry (DSC) apparatus. During the experiment, the heating rate was kept constant at $10^{\circ} \mathrm{C} / \mathrm{min}$ from $600{ }^{\circ} \mathrm{C}$ up to 1450 ${ }^{\circ} \mathrm{C}$, and an argon flow rate of $50 \mathrm{~mL} / \mathrm{min}$ was maintained throughout. The DSC traces presented in this study are from the heating portion of the experiment. The samples used were approximately $5 \mathrm{~mm}$ in diameter and $1.5 \mathrm{~mm}$ in thickness, produced by spark-erosion.

\section{$\underline{\text { Strain analysis }}$}

The residual strain present in the material from the ingot-to-billet conversion operations was evaluated using local misorientation values from electron backscatter diffraction (EBSD) data. This technique can effectively "assess plastic deformation" in the crystal lattice by measuring the effects of plasticity in the form of lattice bending and geometrically necessary dislocations (GNDs) [28]. Local misorientation measurements are consistent with the density of GNDs, and can be translated into nominal strain values through correlation techniques [29,30]. The samples were polished to $0.06 \mu \mathrm{m}$ colloidal silica finish and a field emission gun SEM CamScan MX 2600 was used for EBSD mapping, with an accelerating voltage of $25 \mathrm{kV}$, sample tilt of $70^{\circ}$ and working distance of $30 \mathrm{~mm}$. The results were analyzed using Oxford Instruments" HKL Channel 5 software.

Transmission electron microscopy (TEM) has been used to further examine the density of dislocations within the material, as well as to characterize the precipitate morphology and orientation relationship with the matrix. TEM foils were produced from $3 \mathrm{~mm}$ diameter discs. The discs were spark-eroded from slices $0.2-0.3 \mathrm{~mm}$ thick and then twin-jet electropolished with a solution 10 vol.\% perchloric acid in methanol at $-5{ }^{\circ} \mathrm{C}$ and $20,5 \mathrm{~V}$. A Jeol $200 \mathrm{CX}$ microscope was used to examine the samples in the bright field and obtain electron diffraction patterns at an accelerating voltage of $200 \mathrm{kV}$.

\section{$\underline{\text { Hot compression testing }}$}

Double cone specimens (15.8 $\mathrm{mm}$ height, 5 and $19.8 \mathrm{~mm}$ minor and major diameter, respectively) were machined from the core and rim areas of the wrought billet. The compression tests were performed in a Zwick/Roell Amsler HA 250 servo-hydraulic machine at temperatures $925^{\circ} \mathrm{C}, 950{ }^{\circ} \mathrm{C}, 975^{\circ} \mathrm{C}$ and $1000^{\circ} \mathrm{C}$, constant die speed of $0.158 \mathrm{~mm} / \mathrm{s}$, and up to $65 \%$ height reduction. The samples were coated with a special glass powder to reduce friction with the tool during compression, heated to test temperature at $\sim 12{ }^{\circ} \mathrm{C} / \mathrm{min}$ and then soaked for either $15 \mathrm{~min}$ or 3 hours. In order to preserve the forged microstructure, all specimens were water quenched immediately after compression with a transfer time of less than $30 \mathrm{~s}$ (a detailed description of the compression tests and microstructural results will be published elsewhere).

\section{Results and Discussion}

\section{$\underline{\text { As-received wrought billet }}$}

The microstructure of the as-received billet has been investigated by means of SEM and EBSD at four locations in the axial-radial section, at $0,0.35,0.6$ and 0.95 radius from the billet center (see Figure 1). Backscatter electron (BSE) micrographs of the core and rim regions are presented 
in Figure 2a. Apart from the customary presence of MC-type carbides, nitrides and carbonitrides (fundamentally $\mathrm{NbC}$ and $\mathrm{TiN}$ ), a small trace of $\eta / \delta$ phase particles $(<0.1$ area $\%$ ) is apparent only in close vicinity to the billet rim, while the rest of the volume is essentially precipitate-free. Both grain size and residual strain vary noticeably along the radius: from larger grains in the core, to smaller and more deformed grains in the rim. The presence of fractured carbides near the outer edge of the billet also suggests high levels of strain in the rim area.

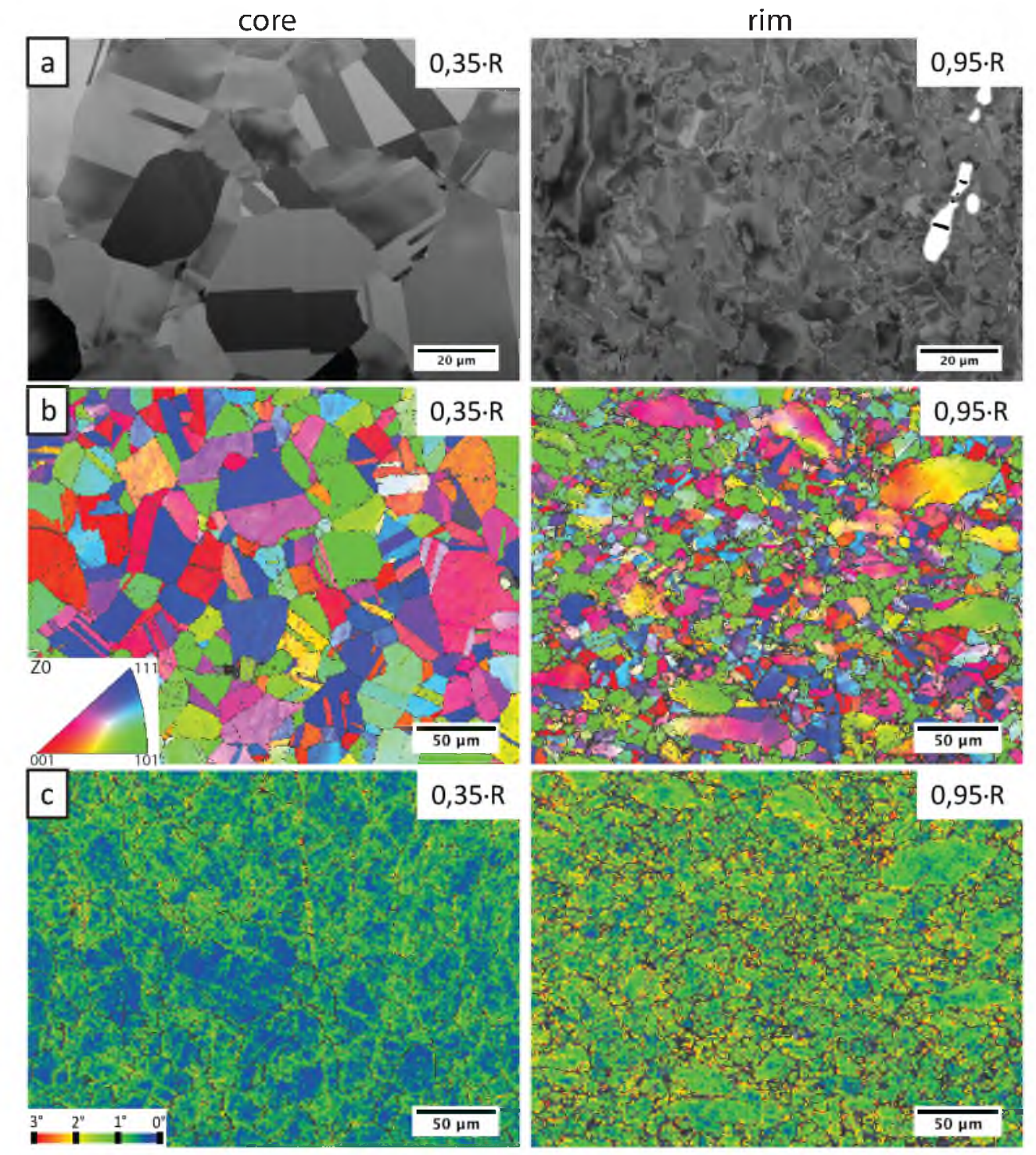

Figure 2. Microstructure of as-received billet material in the core and rim locations.

(a) BSE micrographs; (b) EBSD orientation map; (c) EBSD local misorientation map.

The EBSD cartographies of the same four locations provide a precise description of the grain structure and confirm the increase in lattice plasticity towards the surface of the billet. Areas of $450 \times 300 \mu \mathrm{m}^{2}$ were scanned on each sample with a step size of $0.9 \mu \mathrm{m}$ and square pixels. The grain boundaries were characterized by a misorientation larger than $15^{\circ}$ between neighboring measurement points. Figure $2 \mathrm{~b}$ shows two sub-sections of scanned areas in core and rim. The grain size decreased from an average ASTM 8 at the billet center to ASTM 12 close to the surface. Despite the finer average grain size in the rim region, a number of large unrecrystallized grains are present in the outermost location (0.95R) that appear to be highly deformed, with lattice rotations as high as $90^{\circ}$ in some cases. 
The local misorientation maps in Figure $2 \mathrm{c}$ have been calculated from the EBSD data using the kernel average center misorientation $(\mathrm{KACM})$ method, with a $2^{\text {nd }}$ nearest neighbor kernel size and an exclusion angle of $5^{\circ}$ for post-processing. They confirm the substantial increase in local misorientation, from average values of $0.5^{\circ}$ in the center to $1.5^{\circ}$ towards the surface of the billet, indicative of higher lattice strain and dislocation density. Both the grain size and strain profiles observed are likely to be a consequence of the conditions during the ingot-to-billet conversion operation [31].

\section{Kinetics of secondary phase precipitation}

In order to produce a TTT diagram of $\eta$ and $\delta$ precipitation in 718Plus wrought billet material, cube samples from the core and rim regions were heat-treated between $925^{\circ} \mathrm{C}$ and $1000^{\circ} \mathrm{C}$, and from 20 min up to 10 hours. The measured $\eta+\delta$ area fractions have been plotted in Figure 3 and show precipitation kinetics significantly faster in the billet rim than in the core. For both locations, the fastest precipitation rates occur at $950^{\circ} \mathrm{C}$, but even after a 10 -hour annealing time, the core exhibits lower precipitate fractions. The greater dispersion in the measurements on core samples is due to a finer precipitate morphology, which is more difficult to threshold accurately, and selective boundary precipitation that results in a more inhomogeneous microstructure.
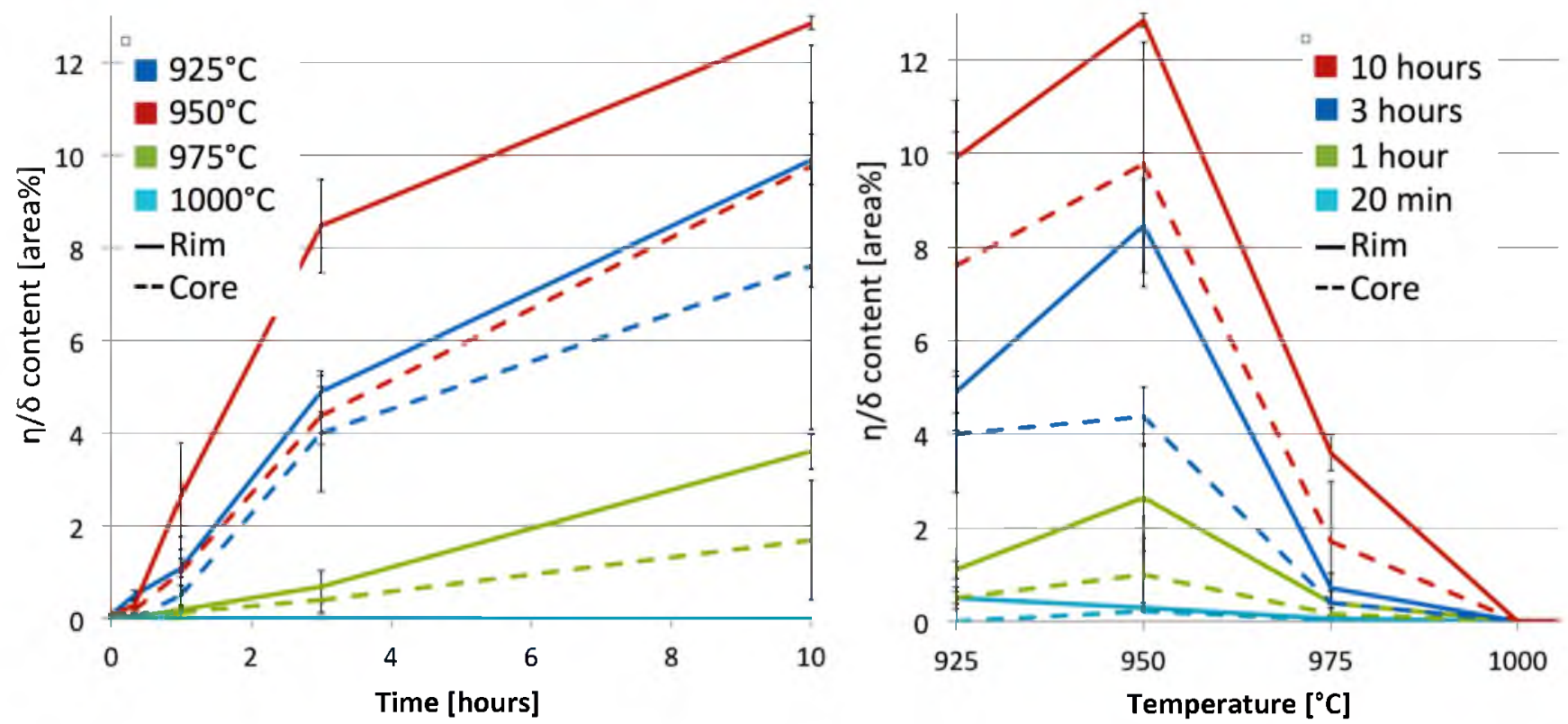

Figure 3. Fraction of $\eta+\delta$ phases precipitated as a function of heat treatment time and temperature. Error bars represent \pm 1 standard deviations.

Attempts to predict the equilibrium volume fraction of the $\eta$ and $\delta$ phases using the Thermo-Calc software package (database: TT Ni-Alloys version 8) were unsuccessful within the range of temperatures considered. In most conditions, it is necessary to suppress $\delta, \gamma^{\prime}$ and $\gamma^{\prime \prime}$ from the computation in order to predict $\eta$ phase, and the volume fractions predicted for $\eta+\delta$ are much lower than the experimental results. For this reason, the equilibrium volume content of $\eta+\delta$ has been estimated experimentally at $900^{\circ} \mathrm{C}$ and $960^{\circ} \mathrm{C}$ by a longer heat treatment for 81 hours. The microstructures after annealing and the precipitate area fractions are presented in Figure 4 . The close estimated values of precipitate content in rim and core suggest thermodynamical equilibrium, where the influence of the starting material has been neutralized, although there are clear differences in the precipitate morphology that will be discussed later. 
Experimentally, the solvus temperature of the $\eta$ and $\delta$ phases was found to be slightly below $1000^{\circ} \mathrm{C}$, as heat treatment at that temperature would dissolve the traces of residual precipitation present in starting material from the rim. Although early literature on 718Plus [5,7] reported $\delta$ solvus temperatures as high as $1065^{\circ} \mathrm{C}$, obtained from thermodynamic calculations, the present result is in agreement with more recent studies, which placed the $\delta$ solvus around $980{ }^{\circ} \mathrm{C}-1000$ ${ }^{\circ} \mathrm{C}[28,30]$. The exception is a study by Srinivasan et al. [23], which indicates a solvus temperature between $1010^{\circ} \mathrm{C}$ and $1071{ }^{\circ} \mathrm{C}$, although after annealing times of only 6 minutes. For heat treatments at $925^{\circ} \mathrm{C}$ and $950{ }^{\circ} \mathrm{C}$ the etching revealed the presence of spherical $\gamma^{\prime}$ particles, indicating that the solvus temperature of the $\gamma^{\prime}$ phase is between $950{ }^{\circ} \mathrm{C}$ and $975{ }^{\circ} \mathrm{C}$. Again, thermodynamical calculations have generally overestimated the $\gamma^{\prime}$ solvus at around $990{ }^{\circ} \mathrm{C}[5,7]$, but DTA and XRD measurements, and TEM observations have lowered that value to the range $955^{\circ} \mathrm{C}-960^{\circ} \mathrm{C}$, which is in better agreement with the current observations $[5,23]$.
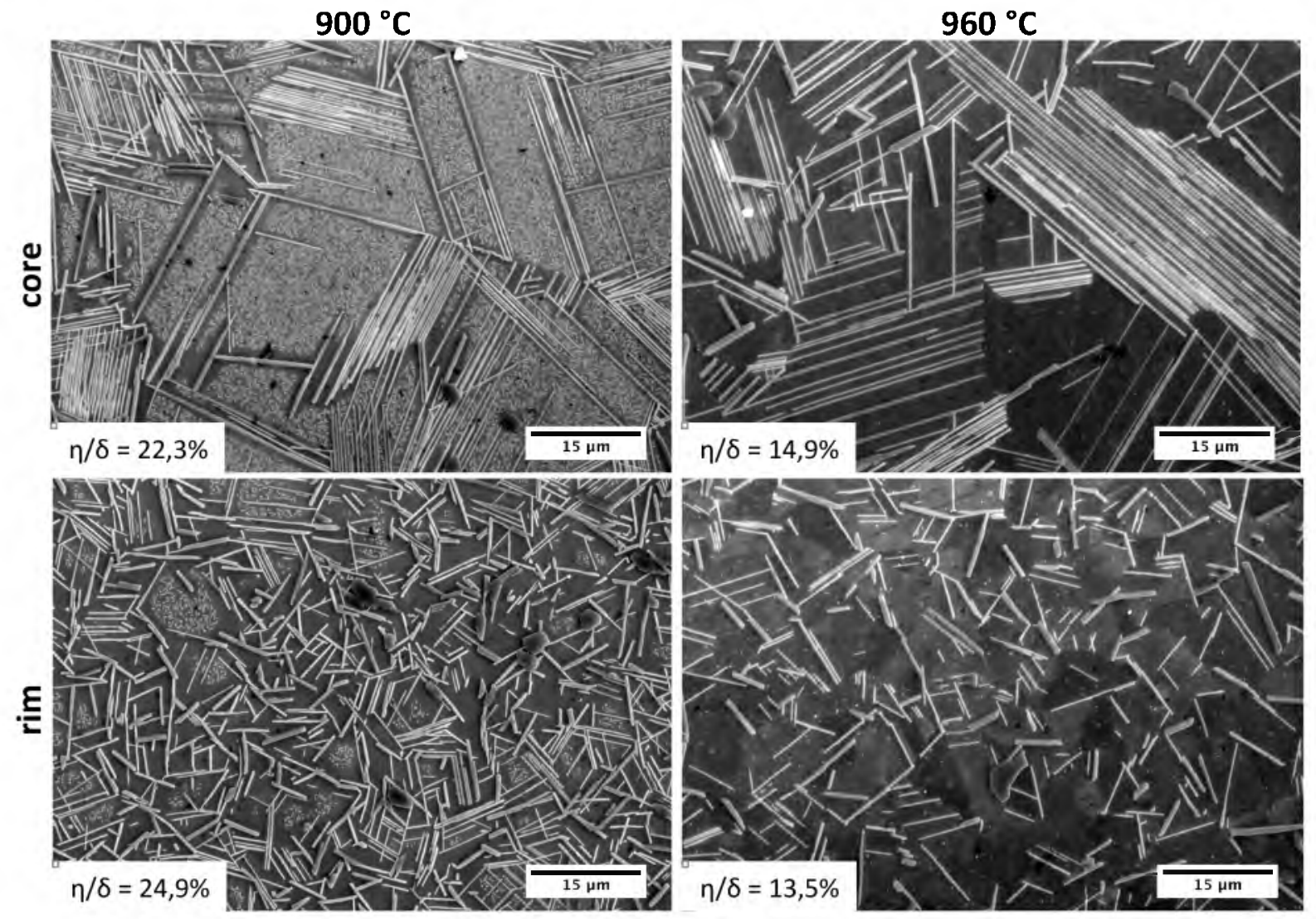

Figure 4. SE micrographs of billet material from the core and rim locations after heat treatment during 81 hours at temperatures $900{ }^{\circ} \mathrm{C}$ and $960^{\circ} \mathrm{C}$. Estimated $\eta / \delta$ contents in area $\%$.

DSC measurements, outlined in Figure 5, were performed in order to confirm the experimental results. The solvus temperatures of the different phases have been defined at the inflection point of the DSC signal, and calculated by fitting the local maximum in the $1^{\text {st }}$ derivative of the heating curve. The results obtained are $\mathrm{T}_{\gamma^{\prime}}=967^{\circ} \mathrm{C}$ and $\mathrm{T}_{\eta, \delta}=1012{ }^{\circ} \mathrm{C}$, with the onset temperature for the dissolution process at $963{ }^{\circ} \mathrm{C}$ for $\gamma^{\prime}$ and $998{ }^{\circ} \mathrm{C}$ for $\eta$ and $\delta$, in accordance with the microstructural observations. Any difference in solvus temperatures between the $\eta$ and $\delta$ phases, could not be resolved with this experiment. However, preliminary data from a synchrotron X-ray diffraction experiment show that the two phases have indeed different solvus temperatures, with that of $\delta$ being slightly higher. The complete results will be published elsewhere. 


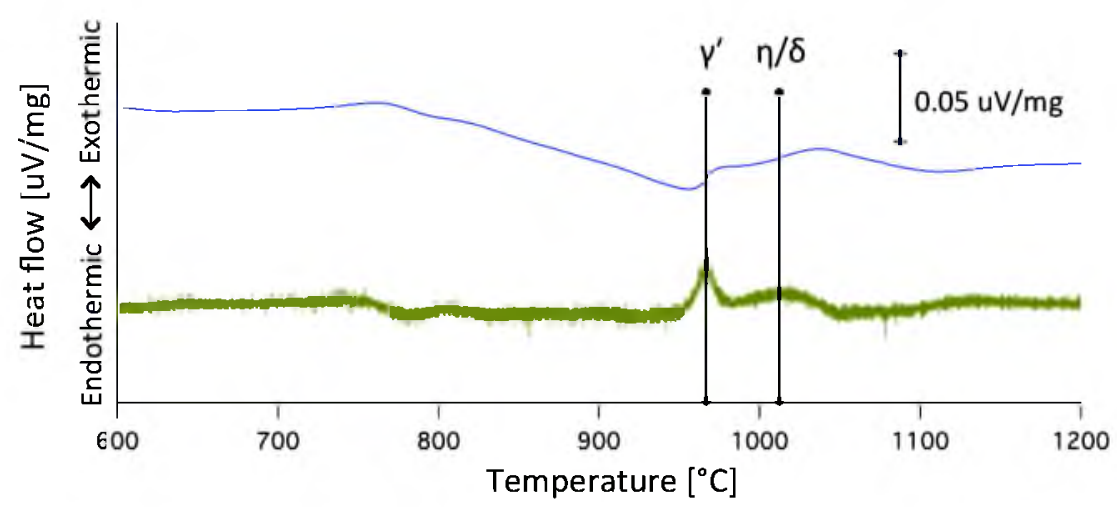

Figure 5. DSC heating curve of 718Plus material (blue) and its $1^{\text {st }}$ derivative (green)

The precipitation data in Figure 3 was fitted using $2^{\text {nd }}$ order polynomials, and the annealing times for specific phase content interpolated to produce the TTT diagram in Figure 6. As expected, the nose appears to be slightly below $950{ }^{\circ} \mathrm{C}$. The shape and nose of the diagram correlate very well with the results by Stotter et al. [25], although their diagram is shifted towards shorter times, probably due to differences in the starting material. The structural results obtained in this study reflect the behavior of small samples that were given various single heat treatments, and therefore reflect accurately the local material behavior. In large components, where thermal delays lead to slower transformation, the nose of the curves is likely to shift to the longer times, even if the shape of the curves is expected to remain similar [17].

\section{Time [hours]}

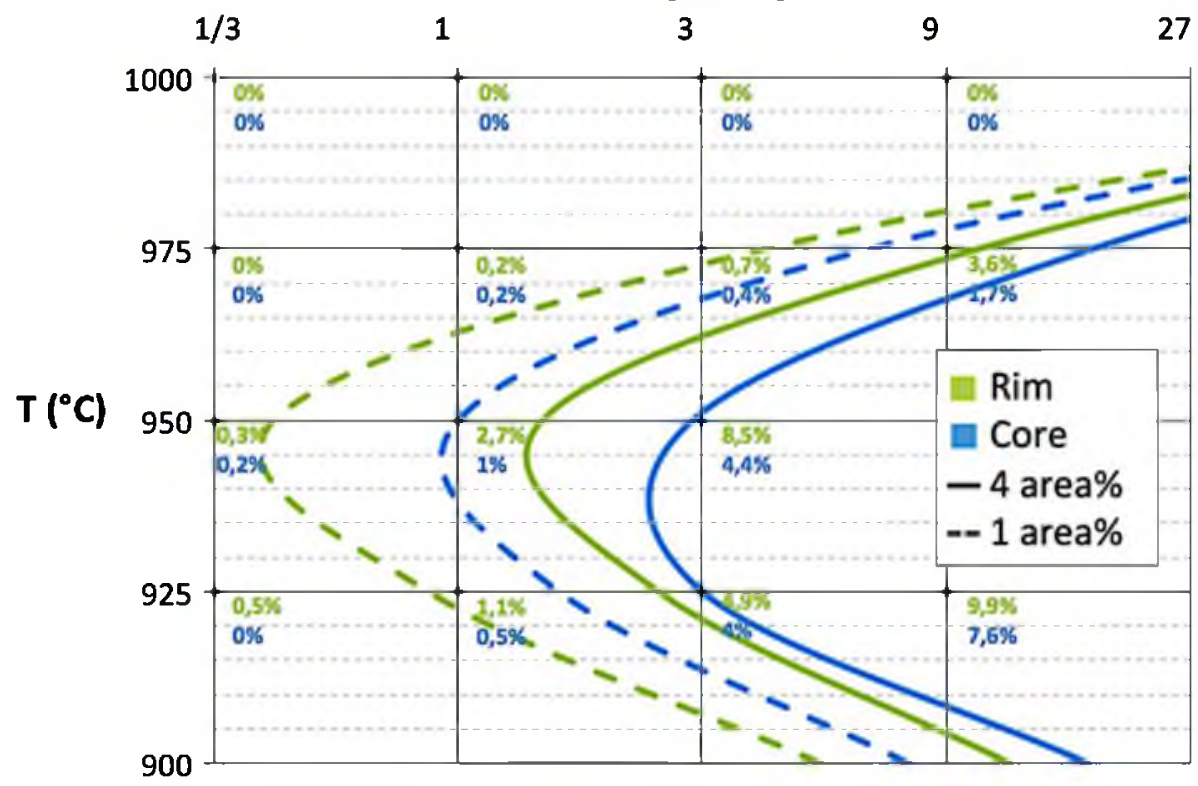

Figure 6. TTT diagram of $\eta / \delta$ phase precipitation in 718Plus wrought billet

\section{Morphology of secondary phase precipitation}

The core and rim regions of the billet exhibit different precipitation kinetics, but other features of the $\eta / \delta$ precipitation are also location specific. As illustrated by Figure 4 , the precipitate structure is more homogeneous in the billet rim, where the particles also tend to adopt the shape of coarse plates. In the core area, on the other hand, cascades of thin lamellae nucleate at selected grain boundaries and grow throughout the host grain. At shorter annealing times (see Figure 7), the same features are observed, as well as selective precipitation in the core region. 

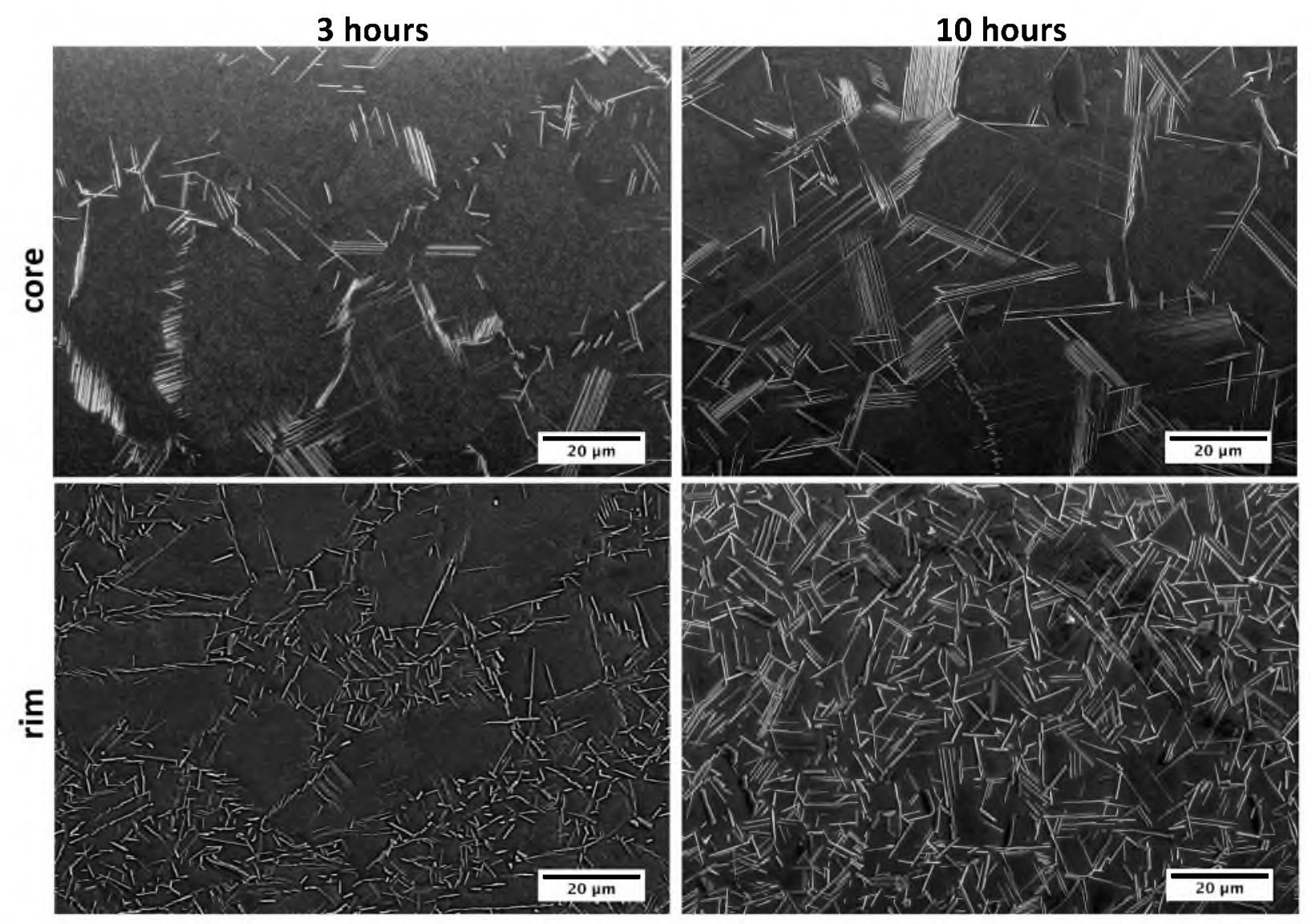

Figure 7. $\eta / \delta$ phase precipitation after annealing at $950{ }^{\circ} \mathrm{C}$ for 3 and 10 hours

The initial microstructures in the billet core and rim differ both in terms of grain size and residual strain in the matrix. It is well established in the published literature on alloys 718 and 718 Plus that the beginning and attainable volume fraction of secondary phase precipitation is dependent on the degree of residual strain in the starting material [26,27]. However, no information is available on the influence of grain size on grain boundary precipitation in 718 Plus.

In order to ascertain the origin of the differences in precipitate morphology, a third location was examined. Figure 8 shows the microstructure in the billet surface, in the tangential orientation, after a 3-hour exposure at $950^{\circ} \mathrm{C}$. The residual strain in this area is the highest within the billet, and EBSD data is not available due to the poor quality of the Kikuchi patterns. The grains, despite being heavily deformed, have not recrystallized and maintain a larger size, which allows comparison of the effects of grain size and strain. It is observed that in the presence of sufficient lattice strain in the matrix, massive secondary phase precipitation occurs, with rapid nucleation in grain boundaries, twins and intragranularly, regardless of grain size. At the same time, the lattice rotation hinders the longitudinal growth of the precipitates, which need to bend in order to follow the close-packed planes in the matrix, and promotes a disc-like morphology. The thickness of the precipitates is limited by the competition for $\eta / \delta$-forming elements, which are rapidly exhausted due to the high nucleation rates. It can be concluded that the effect of residual strain in $\eta / \delta$ precipitation is the major one, and can induce significant variations in the morphology, grain boundary coverage and fraction of secondary phase precipitation. 

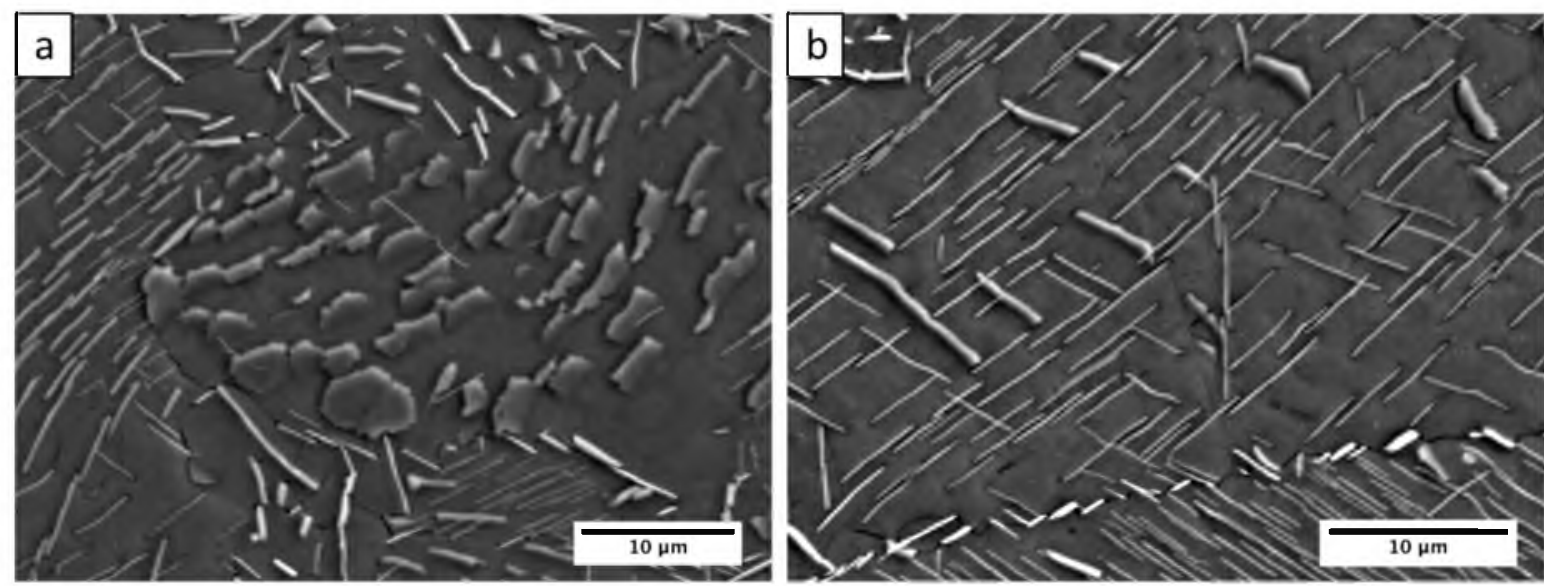

Figure $8 . \eta / \delta$ phase precipitation in the billet surface after annealing at $950^{\circ} \mathrm{C}$ for 3 hours

A closer investigation of the particle morphology by TEM has permitted the investigation of the role of strain and lattice bending on the growth of the precipitates in different conditions. Figure 9 shows a colony of lamellar $\eta / \delta$ precipitates growing transgranularly. The selected area diffraction pattern (SADP) confirms that the particles grow coherently with the matrix following the Blackburn orientation relationship, as has already been reported for these phases [9]. The dislocation density within the matrix is low, and only isolated dislocations are visible in the relevant grain. The morphology that ensues is that of thin lamellae with a high aspect ratio, as the particles grow confined between the bounding coherent interfaces parallel to close-packed planes in the matrix. The barrier to growth along the thickness direction of the plate-like precipitates is the low energy of the coherent interface. In such case, the lateral growth of the precipitates is often governed by a ledge-wise mechanism, and the large difference in the relative mobility of growing interphase boundaries yields a highly elongated plate morphology [32].
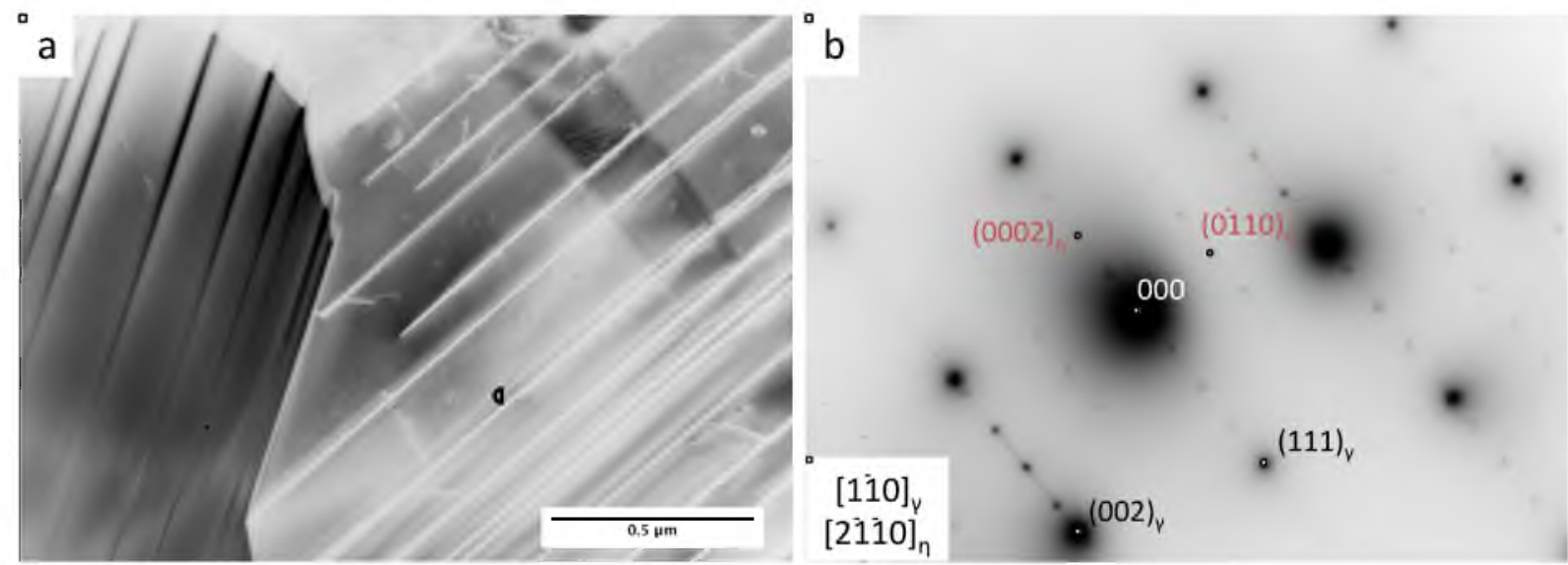

Figure 9. (a) Site of SADP in core billet material heat-treated at $950{ }^{\circ} \mathrm{C}$ for 10 hours; (b) $[2 \overline{1} \overline{1} 0]_{\eta}$ $+[1 \overline{1} 0]_{\gamma}$ patterns obtained from a colony of lamellar $\eta / \delta$ precipitates and the surrounding matrix

In the rim area, the dislocation density in the matrix is higher, as shown by Figure 10a, and they interact actively with the precipitate interface. Figure 10b illustrates the coarser morphology that has been identified in the rim region, and the effect of lattice bending on particle growth. In the figure we can observe a group of precipitates penetrating a region of different orientation from their area of origin. In order to adjust to the surrounding matrix, the particles bend and grow thicker as their interface becomes less coherent and more mobile. 

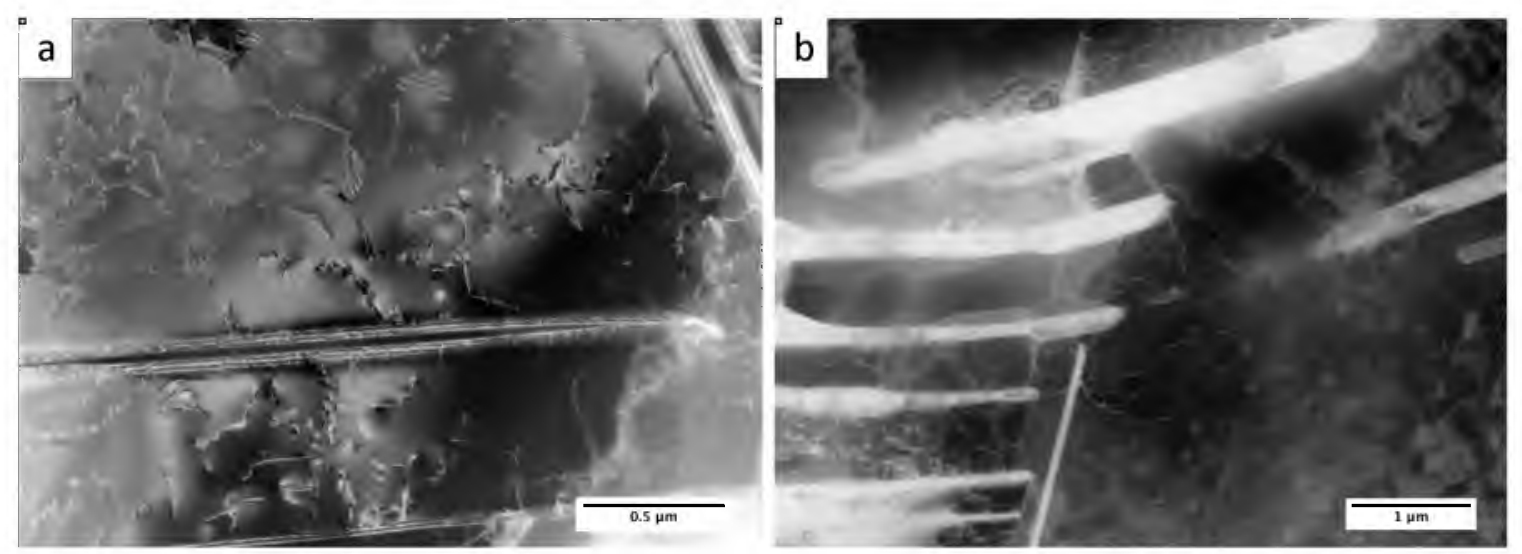

Figure 10. TEM bright field images of $\eta / \delta$ precipitates in rim billet material heat-treated at 950 ${ }^{\circ} \mathrm{C}$ for 10 hours

It can be concluded that residual lattice strain in the matrix, in the form of dislocation density and/or lattice rotation, not only influences the precipitate volume fraction, but also particle morphology and location. Dislocations enhance diffusion through the bulk and serve as nucleation sites for intragranular precipitation. Lattice rotation, which is also accompanied by the presence of GNDs, prevents elongated plates from keeping a coherent interface with the matrix and promotes a coarser plate-like morphology. In the billet core, with large recrystallized grains and low dislocation densities, the precipitates nucleate in grain boundaries and grow coherently forming cascades of lamellae. In the rim, the particles lose coherency as they grow through grains with high lattice rotations, while the high dislocation densities in the matrix enhance diffusion and allow for the fast growth of the incoherent and semicoherent interfaces. It follows from these results that any manufacturing operation prone to modifying the coherency of the precipitate-matrix interface, i.e. by deformation or recrystallization of the matrix, will promote a coarse morphology of the existing precipitates.

\section{Hot compression tests}

The precipitation of secondary phases during heating before sub-solvus forging, which typically ranges between $30 \mathrm{~min}$ and 3 hours in an industrial context, has an effect not only on the developing microstructure, but also on the compression flow stresses. Hot compression tests have been performed on double-cone specimens issued from the core and rim of the billet, at temperatures between $925^{\circ} \mathrm{C}$ and $1000{ }^{\circ} \mathrm{C}$. In order to asses the extent of load partitioning to the second phases $\eta$ and $\delta$ during forging, half of the samples tested were held at forging temperature for 3 hours before deformation to promote precipitation. The load-stroke curves are represented in Figure 11a, from which the loads at $60 \%$ height reduction for each sample have been obtained and plotted in Figure $11 \mathrm{~b}$.

At forging temperatures $925^{\circ} \mathrm{C}$ and $950{ }^{\circ} \mathrm{C}$, the 3-hour hold time results in reduced die loads. This has been attributed to the presence of strengthening $\gamma^{\prime}$ particles that precipitate during heating, and are subsequently overaged during the time at temperature. At $975{ }^{\circ} \mathrm{C}, \gamma^{\prime}$ dissolves and the only effect from the hold time is the precipitation of secondary phases, which results in load increases of around 7\% for rim and 5\% for core material. The greater strengthening effect in samples issued from the rim area can be explained by the higher $\eta / \delta$ phase content and coarser morphology. The higher loads required to compress samples from the billet core at all conditions are associated with the larger grain size and therefore better creep resistance of the starting material. 

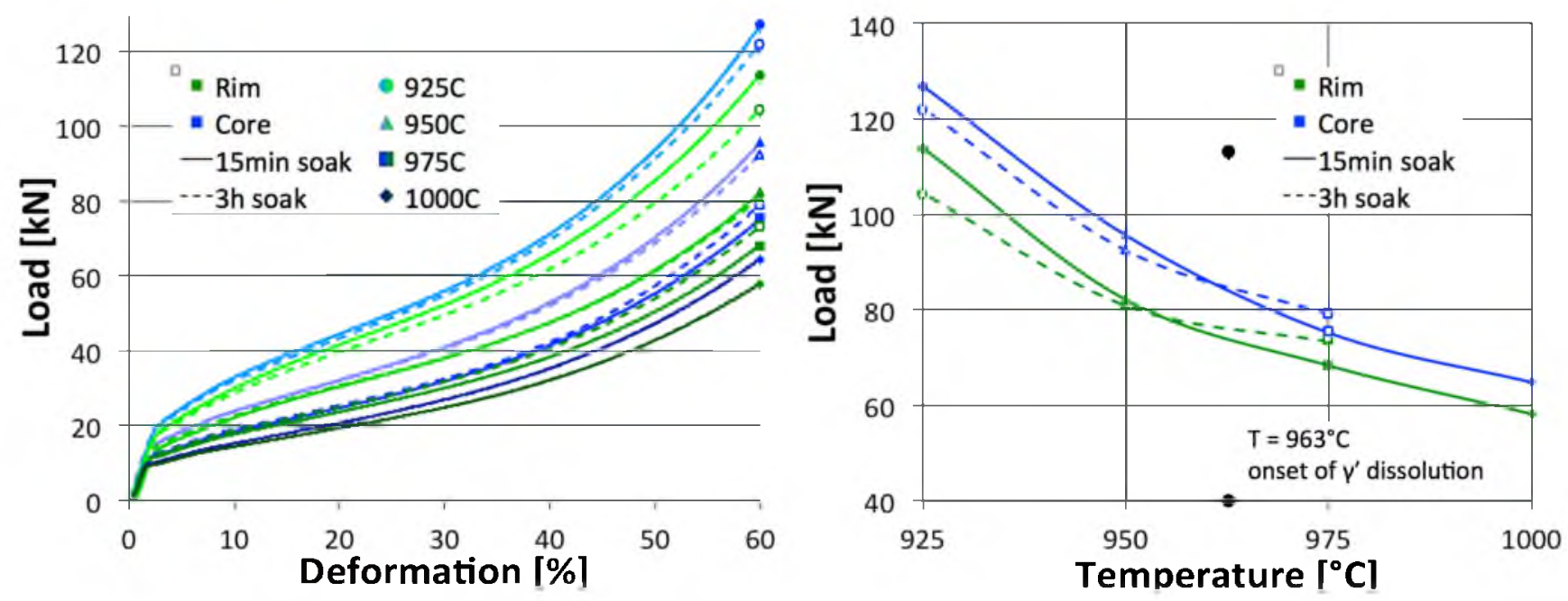

Figure 11. (a) Load-stroke curves of double-cone compression tests. (b) Load for $60 \%$ height reduction.

\section{Conclusions}

During processing of alloy 718 Plus components, substantial precipitation of secondary phases $\eta$ and $\delta$ takes place in the wrought billet during heating before sub-solvus forging. The local strain conditions along the billet were found to have a major influence on the precipitate fraction, morphology and location. The center of the billet, with an initial structure of large recrystallized grains, has slower precipitation kinetics than the surface, with smaller grains and higher strain levels. This results in lower precipitate fractions at all temperatures between 925 and $1000^{\circ} \mathrm{C}$ for annealing times up to 10 hours.

A TTT diagram of $\eta / \delta$ precipitation in the billet has been provided that indicates these differences, with the nose temperature slightly below $950{ }^{\circ} \mathrm{C}$ for both the center and surface of the billet. The experimental solvus temperature for the $\gamma^{\prime}$ and $\eta / \delta$ phases were confirmed with DSC measurements, which determined a maximum solution rate at $967{ }^{\circ} \mathrm{C}$ for $\gamma^{\prime}$ and $1012^{\circ} \mathrm{C}$ for $\eta / \delta$, with the onset temperatures being 963 and $998^{\circ} \mathrm{C}$ respectively.

For all annealing temperatures, two distinct precipitate morphologies were found throughout the billet: colonies of thin lamellae, which predominate in the bulk, and coarse plates, widespread closer to the surface. Between initial grain size and residual strain, the latter was found to determine the morphology of the $\eta / \delta$ particles in two ways: lattice rotation, resulting in reduced coherency between the precipitate and the matrix; and dislocation density, which increases bulk diffusion and accelerates the growth of incoherent interfaces. Thus, precipitates in strained regions, such as the surface of the billet, develop semi- or incoherent interfaces and coarsen into thick plates, while those forming in strain free grains grow coherently into thin lamellae. Forging operations, through deformation and recrystallization processes, can affect the coherency of the precipitate-matrix interface and change the growth mechanism of existing particles.

The effect of $\eta / \delta$ precipitation in the billet on the compression flow stresses is stronger in material from the outer edge of the billet, due to the higher volume fractions and, possibly, the morphology of the precipitates. The load increase associated with precipitation annealing is only noticeable at temperatures near or above the $\gamma^{\prime}$ solvus. At lower temperatures, the overaging of the strengthening $\gamma^{\prime}$ particles counteracts any influence from the secondary phases. 


\section{Acknowledgments}

This work is related to a comprehensive research program on alloy ATI 718Plus conducted at Rolls-Royce Deutschland Ltd. \& Co KG and funded by the German Bundesministerium für Wirtschaft und Technologie (BMWi) under grant number 20T0813. The financial support from Rolls-Royce plc and the UK Engineering and Physical Sciences Research Council (EPSRC) under EP/H500375/1 is also gratefully acknowledged. A. Casanova wishes to further extend her thanks to the Fundación Caja Madrid Trust for their sponsorship.

\section{References}

[1] R. Kennedy, "Allvac ${ }^{\circledR} 718$ Plus $^{\mathrm{TM}}$, superalloy for the next forty years," in Superalloys 718 \& Derivatives (2005), 1-14.

[2] M. Springmann, W. Rothkegel, D. Huenert, and H. Schlums, "Introduction of the new nickel-base alloy ATI 718Plus $®$ for critical parts," in 7th International Conference on Low Cycle Fatigue (2013).

[3] L. Viskari, Y. Cao, M. Norell, G. Sjöberg, and K. Stiller, "Grain boundary microstructure and fatigue crack growth in Allvac 718Plus superalloy," Mater. Sci. Eng. A, 528 (6) (2011), $2570-2580$.

[4] K. Löhnert and F. Pyczak, "Microstructure evolution in the nickel base superalloy Allvac 718PlusTM," in Superalloys 718 \& Derivatives (2010), 877-891.

[5] W. D. Cao, "Solidification and solid state phase transformation of Allvac® 718 Plus ${ }^{\text {TM }}$ alloy," in Superalloys 718 \& Derivatives (2005).

[6] W. Cao and R. Kennedy, "New developments in wrought 718-type superalloys," Acta Metall. Sin., (2005).

[7] X. Xie, C. Xu, G. Wang, J. Dong, W. D. Cao, and R. Kennedy, "TTT diagram of a newly developed nickel-base superalloy - Allvac® 718Plus ${ }^{\mathrm{TM}}$," Mater. Res., (2005), 193-202.

[8] X. Xie, G. W. J. Dong, C. Xu, W. D. Cao, and R. Kennedy, "Structure stability study on a newly developed nickel-base superalloy - Allvac® 718plus ${ }^{\mathrm{TM}}$," in Superalloys 718 \& Derivatives (2005), 179-191.

[9] E. J. Pickering, H. Mathur, A. Bhowmik, O. M. D. M. Messé, J. S. Barnard, M. C. Hardy, R. Krakow, K. Loehnert, H. J. Stone, and C. M. F. Rae, "Grain-boundary precipitation in Allvac 718Plus," Acta Mater., 60 (2012), 2757-2769.

[10] O. Messé, J. Barnard, E. Pickering, P. Midgley, and C. Rae, "On the precipitation of delta phase in ALLVAC 718Plus," Philos. Mag., (2014).

[11] K. Löhnert, "Einfluss der thermomechanischen Vorbehandlung auf die Eigenschaften der Nickelbasissuperlegierung A718Plus" (Ph.D. thesis, Universität Erlangen-Nürnberg, 2011).

[12] S. Oppenheimer, E. McDevitt, and W. D. Cao, "Toughness as a function of thermomechanical processing and heat treatment in 718Plus (B) superalloy," in Superalloys 718 \& Derivatives (2010), 321-330.

[13] W. D. Cao and R. Kennedy, "Recommendations for heat treating of Allvac 718Plus alloy parts," (Allvac Technical Report, 2006).

[14] H. L. Eiselstein, "Metallurgy of columbium-hardened nickel-chromium iron alloy," Am. Soc. Test. Mater. Spec. Tech. Publ., (1965), 62-79. 
[15] W. J. Boesch and H. B. Canada, "Precipitation reactions and stability of Ni3Cb in Inconel alloy 718," in International Symposium on Structural Stability in Superalloys, 21 (10) (1968), 579-596.

[16] J. W. Brooks and P. J. Bridges, "Metallurgical stability of Inconel alloy 718," in Superalloys (1988), 33-42.

[17] A. Oradei-Basile and J. Radavich, "A current TTT diagram for wrought alloy 718," in Superalloys (1991).

[18] I. Kirman and D. Warrington, "The precipitation of Ni3Nb phases in a Ni-Fe-Cr-Nb alloy," Metall. Trans., 1 (1970), 2667-2675.

[19] V. Beaubois, J. Huez, S. Coste, O. Brucelle, and J. Lacaze, "Short term precipitation kinetics of delta phase in strain free Inconel* 718 alloy," Mater. Sci. Technol., 20 (8) (2004).

[20] M. Sundararaman, "Precipitation of the Delta (Ni3Nb) phase in two nickel base superalloys," Mater. Trans. A, 19 (1988), 453-465.

[21] W. Liu, M. Yao, and Z. Chen, "Effect of cold rolling on the precipitation behavior of $\delta$ phase in INCONEL 718," Metall. Mater. Trans. A, 30 (1999).

[22] Y. Huang and T. G. Langdon, "The evolution of delta-phase in a superplastic Inconel 718 alloy," J. Mater. Sci., 42 (2) (2007), 421-427.

[23] D. Srinivasan, L. Lawless, and E. Ott, "Experimental determination of TTT diagram for alloy 718Plus®," in Superalloys, 3 (2012), 759-768.

[24] R. Radis, G. A. Zickler, M. Stockinger, C. Sommitsch, and E. Kozeschnik, "Numerical simulation of the simultaneous precipitation of $\delta$ and $\gamma$ ' phases in the ni-base superalloy ATI Allvac $\otimes 718$ PlusTM," in Superalloys 718 \& Derivatives, (2010) 569-578.

[25] C. Stotter, "Characterization of d-phase in superalloy Allvac 718Plus," Int. J. Mater. Res., 99 (2008), 376-380.

[26] J. Andersson, G. Sjöberg, and S. Hatami, "Notch sensitivity and intergranular crack growth in the allvac 718plus superalloy," in ISABE Beijing, 1 (11) (2007), 1829-1841.

[27] E. T. McDevitt, "Effect of temperature and strain during forging on subsequent delta phase precipitation during solution annealing in ATI 718Plus ${ }^{\circledR}$ alloy," in Superalloys 718 \& Derivatives (2010), 307-319.

[28] A. J. Schwartz, M. Kumar, and D. P. Field, "Mapping and assessing plastic deformation using EBSD," in Electron Backscatter Diffraction in Materials Science, Eds. Springer US (2009), 251-262.

[29] R. Yoda, T. Yokomaku, and N. Tsuji, "Plastic deformation and creep damage evaluations of type 316 austenitic stainless steels by EBSD," Mater. Charact., 61 (10) (2010), 913-922.

[30] M. Kamaya, "Measurement of local plastic strain distribution of stainless steel by electron backscatter diffraction," Mater. Charact., 60 (2) (2009), 125-132.

[31] C. Dandre, C. Walsh, and R. Evans, "Microstructural evolution of nickel base superalloy forgings during ingot to billet conversion: process modeling and validation," in Superalloys (2000).

[32] G. J. Shiflet, M. A. Mangan, and W. G. Meng, "Growth by ledges," Interface Sci., 154 (1998), 133-154. 